FERMILAB-Conf-96/293

\title{
Operation and Maintenance of Fermilab's Satellite Refrigerator Expansion Engines
}

\author{
William M. Soyars \\ Fermi National Accelerator Laboratory \\ P.O. Box 500, Batavia, Illinois 60510
}

September 1996

Presented at the Cryogenic Engineering Conference and International Cryogenic Materials Conference (CEC/1CMC 95), Columbus, Ohio, July 17-21, 1995. 


\section{Disclaimer}

This report was prepared as an account of work sponsored by an agency of the United States Government. Neither the United States Government nor any agency thereof, nor any of their employees, makes any warranty, express or implied, or assumes any legal liability or responsibility for the accuracy, completeness or usefulness of any information, apparatus, product or process disclosed, or represents that its use would not infringe privately owned rights. Reference herein to any specific commercial product, process or service by trade name, trademark, manufacturer or otherwise, does not necessarily constitute or imply its endorsement, recommendation or favoring by the United States Government or any agency thereof. The views and opinions of authors expressed herein do not necessarily state or reflect those of the United States Government or any agency thereof.

\section{Distribution}

Approved for public release: further dissemination unlimited. 


\title{
OPERATION AND MAINTENANCE OF FERMILAB'S SATELLITE REFRIGERATOR EXPANSION ENGINES
}

\author{
William M. Soyars \\ Fermi National Accelerator Laboratory* \\ Batavia, Illinois 60510
}

\begin{abstract}
Fermilab's superconducting Tevatron accelerator is cooled to liquid helium temperatures by 24 satellite refrigerators, each of which uses for normal operations a reciprocating "wet" expansion engine. These expanders are basically Process System (formerly Koch) Model 1400 expanders installed in standalone cryostats designed by Fermilab. This paper will summarize recent experience with operations and maintenance of these expansion engines. Some of the statistics presented will include total engine hours, mean time between major and minor maintenance, and frequent causes of major maintenance.
\end{abstract}

\section{INTRODUCTION}

A Fermilab reciprocating expander is shown in Figure 1. The original design and the initial operational experience for Fermilab's expansion engines was described by Peterson. 1 Further operating experience has been described for the first six years of the Tevatron's life, which was commissioned in 1983. 2,3 This paper will update some of these statistics.

There are two different styles of engines used by Fermilab, "wet" engines used to produce liquid helium and "dry" engines used for intermediate cooling of the heat exchanger column. One major change in wet and dry engines has occurred. Prior to summer of 1993, the wet engine had twin reciprocating $5 \mathrm{~cm}$ diameter pistons while the dry engine had $7.5 \mathrm{~cm}$ pistons. In the summer of 1993, the piston sizes were reversed so that wets now have the larger diameter pistons. This was done to accommodate system changes related to the cryogenic system lower temperature upgrade, resulting in warmer expander inlet temperatures. Furthermore, changes have been made to the controllers. The original wets used a $1.5 \mathrm{~kW}$ DC controller, while the new wets now have a $5.6 \mathrm{~kW} \mathrm{AC}$ regenerative controller. ${ }^{4}$ These statistics presented here will help find any changes in maintenance trends since the conversion of $7.5 \mathrm{~cm}$ piston machines into wet engines.

Since normal Tevatron cryogenic system operation uses only the wet engine, run hours and maintenance statistics presented here will be based exclusively on wet engine observations. One would expect maintenance trends to be similar for the dry engine, due to the similar nature of their design.

\footnotetext{
* Work supported by the U.S. Departunent af Energy under contract No. DE-ACO2-76CH03000
} 


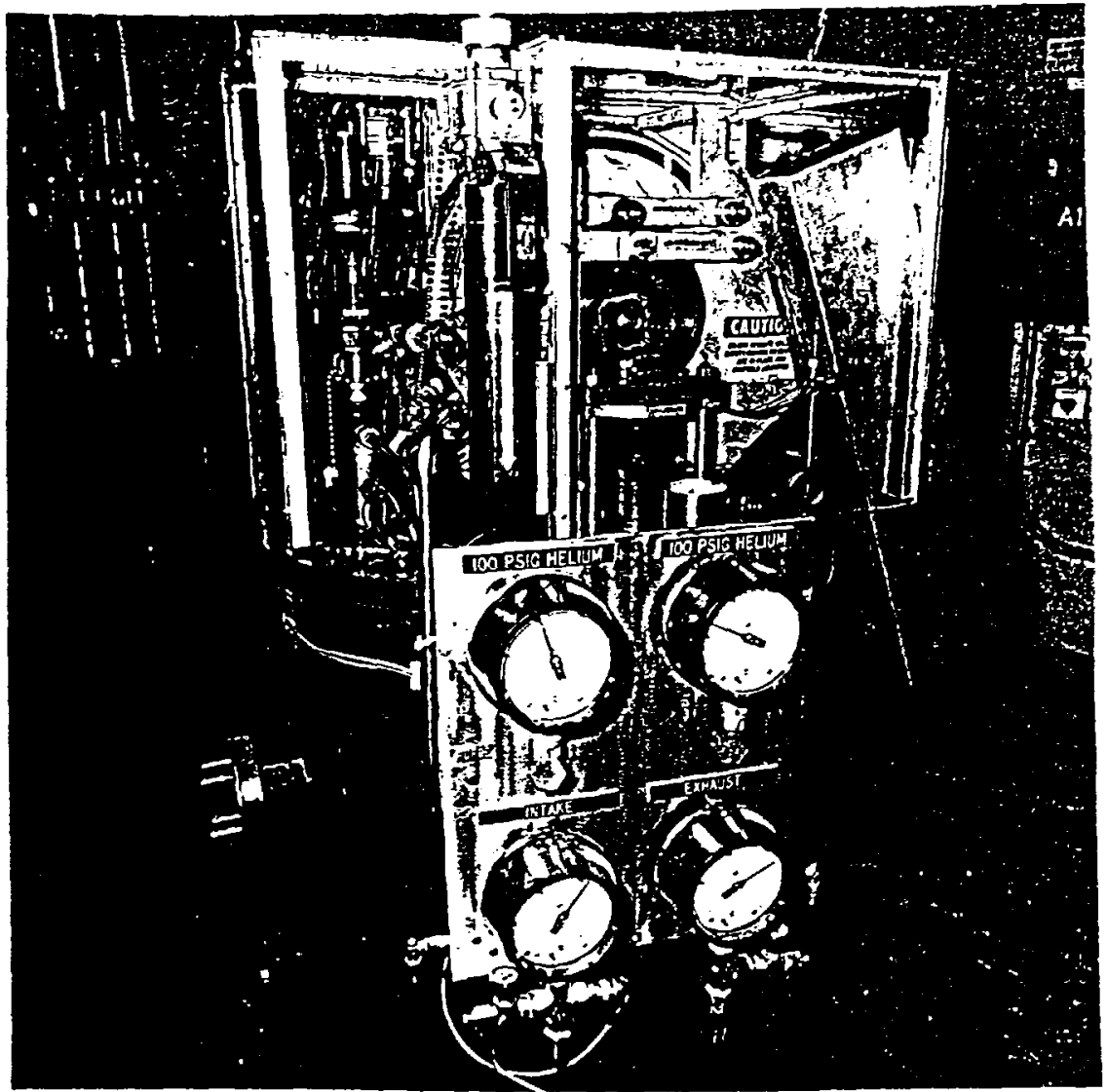

Figure 1. Fermilab wet expansion engine

Table 1. Fermilab modifications to engines

Realignment of frame (top end of the engine, which includes the flywheel assembly)
Alignment controls the main bearing location so that the shaft is apnropriately located with plate. respect to the cylinder centers. Sacrifice a slight bit of alignment to fit definition of an "average" aligument.

Crosshead guide inserts

Crosshead replacement

Bore out the original steel crosshead guides to insert a bronze bushing (upper end) and a chrome sleeve (lower end, where O-ring slides).

Aluminum piston crossheads Longer wear life replaced with ones that are chrome plated steel.

Easier to reuse the crossheads by having them rechromed

Wrist pin bushing
Avoids surface wear and damage in the more expensive crosshead guide.
Makes frames interchangeable, any raune can be used with any top the.
Bore out the wrist pin hole in the Avoids wear in the connecting rod. comnecting rod to accept a bromze bushing 


\section{FERMILAB MODIFICATIONS TO PURCHASED ENGINES}

To completely assess these maintenance statistics, one must be aware of the fact that significant changes are made by Fermilab before installation of an engine into the cryogenic system. Based on our experience, these changes enhance the life, maintainability, and safety of these machines. The modifications that are only for operational preference or safety will not be addressed here. Table 1 details those changes that increase the life and maintainability of our expansion engines.

\section{GENERAL MAINTENANCE ROUTINE}

The reliable operation of the wet expanders is essential to unintermpted operation of the cryogenic system, and therefore the Tevatron accelerator. Because the consequences of an engine failure during physics operations are so severe in terms of lost experimental time, an experimental run typically hegins with all the wet engines completely overhauled. A complete overhaul includes rebuilding the frame, pistons, crosshead guides, valves, and jackshaft. The new components used to rebuild each of these subsystems are shown in Table 2 .

During a physics run, routine maintenance consists of weekly inspections of engines and monthly greasing of bearings and piston crosshead guides. Such routine maintenance is not included in these maintenance statistics. Repairs are made if possible during accelerator down periods, otherwise done on demand.

\section{FAILURE EVENTS TABLE}

Records of engine operation lrom 1988 to 1995 have been reviewed. During this period, there have been six accelerator cryogenic expander runs of varying duration. An expander run is defined as a period that concludes with an extended shutdown in which the liquid helium system is turned off and engine overhaul maintenance occurs. Do not confuse these expander runs with a physics experimental run; a physics run may have different beginning and ending dates. Statistics for this report were collected up to the February 1995 system maintenance shutdown. Information past this point is not included since the present expander run is scheduled to last until the end of July 1995.

Failures of wet engines have heen counted and grouped by failure type. See Table 3. Failures are grouped into two different mechanical categories: major failures and minor failures. A major failure requires the engine to be warmed up from cryogenic temperatures, while a minor failure can be repaired while the engine remains cold (but it must be shut off).

The shaded portion of Table 3 summarizes the failure statistics. Total hours reflect those amassed by all 24 expanders, while average hours represent a typical machine. If one assumes a machine that is repaired upon failure and whose failure rate is constant over time, it is meaningful to define a "mean time between failure" (MTBF) as total operating time divided by number of failures. ${ }^{5}$ However, it is not a simple matter in this case to define a MTBF since it assumes that a given machine runs until at least one failure. Quite often in our case an engine will last the entire run with no failures. Nevertheless, since engines are overhauled prior to beginning the next run, one can detine a "mean time between maintenance" (MTBM) whether or not there was a failure. This time reflects how long an engine has been allowed to operate before perlorming maintenance due to either a failure or an accelerator shutdown. For a given run, for this system of 24 engines:

$$
\overline{M T B M}=\frac{1}{24} \sum_{i=1}^{24} \frac{\text { hours }_{i}}{\text { failures }_{i}+1}
$$

Notice that a MTBM for minor repairs was not calculated for the 1993-94 run perind. In this case, the majority of warm components, which are those involved in minor repairs, were not overhauled at the end of this run. Since this led to additional service hours, this run's minor failures are accounted for in the 1994-95 minor MTBM calculation. This calculation also includes four frame components that were overhauled as normal at the run's completion. Its interesting to note that ten fiame assemblies survived the 10,800 hours during the combined last two runs with no lailures. 
Table 2. Parts replaced during engine overhaul

\begin{tabular}{|c|c|c|c|c|}
\hline Frame & Pistons & $\begin{array}{l}\text { Crosshead } \\
\text { Guides }\end{array}$ & Valves & Jackshaft \\
\hline mklin cradushlaft & O-rings and felts & bronze bushing & $\begin{array}{l}\text { valve aun bearings } \\
\text { valve amn bushings }\end{array}$ & shadt \\
\hline main bearings & : wrist pins & chrome sleeve & cum bearings & bealrings \\
\hline $\begin{array}{l}\text { connecting rod bearings } \\
\text { connecting rod bushings }\end{array}$ & wist pin txát ings. & O-ring scal & $\begin{array}{l}\text { valve seats } \\
\text { O-rings and felts }\end{array}$ & puls \\
\hline
\end{tabular}

Table 3. Failure Incidences for 24 wet engines during accelerator operations

\begin{tabular}{|c|c|c|c|c|c|c|c|}
\hline Problem & $\begin{array}{l}\text { repair time } \\
\text { (hours) }\end{array}$ & $94-95$ & $93-94$ & 92.93 & $90-92$ & 90 & 88.89 \\
\hline $\begin{array}{l}\text { O-ring } \\
\text { Blow by }\end{array}$ & 4 & 2 & 4 & 5 & 4 & 0 & 8 \\
\hline $\begin{array}{l}\text { Genl Pist } \\
\text { overhaul }\end{array}$ & 4 & 0 & 0 & 2 & 0 & 1 & 2 \\
\hline $\begin{array}{l}\text { Connect. } \\
\text { Rod }\end{array}$ & 4 & 0 & 1 & 1 & 0 & 0 & 0 \\
\hline $\begin{array}{l}\text { Wrist } \\
\text { Pin }\end{array}$ & 4 & 0 & 2 & 2 & 1 & 1 & 0 \\
\hline $\begin{array}{l}\text { Internal } \\
\text { Leak }\end{array}$ & 6 & 0 & 0 & 0 & 2 & 0 & 0 \\
\hline $\begin{array}{l}\text { Frame- } \\
\text { main brg }\end{array}$ & 1 & 4 & 1 & 0 & 0 & 0 & 2 \\
\hline $\begin{array}{l}\text { Frame- } \\
\text { general }\end{array}$ & 1 & 2 & 1 & 3 & 0 & 0 & 0 \\
\hline Crankshaft & 1 & 0 & 5 & 0 & 0 & 0 & 0 \\
\hline $\begin{array}{l}\text { Jackshaft } \\
\text { and brg }\end{array}$ & 1 & 0 & 1 & 4 & 2 & 1 & 0 \\
\hline $\begin{array}{l}\text { Connect. } \\
\text { rol bre }\end{array}$ & 1 & 1 & 1 & 1 & 4 & 0 & 0 \\
\hline $\begin{array}{l}\text { Valve } \\
\text { Iod/ann }\end{array}$ & 0.5 & 2 & 2 & 1 & 4 & 3 & 2 \\
\hline $\begin{array}{l}\text { Valve } \\
\text { change }\end{array}$ & 0.5 & 0 & 2 & 1 & 1 & 5 & 19 \\
\hline \multicolumn{2}{|c|}{ tot hrs $=4, \mathrm{~s}, \mathrm{~s}$} & $\therefore 88645$ & 170934 & .246824 & 230819 & 140497 & 235301 \\
\hline \multicolumn{2}{|c|}{ avg hrs $=4, A$} & 3694 & 7122 & 10248 & -9617 & 5.5854 & 9804 \\
\hline \multicolumn{2}{|c|}{ MTBM \&yitmajor) } & $.3540^{x}$ & $\because 6083 x$ & 88113 & 8215 & 5610 & 7762 \\
\hline \multicolumn{2}{|c|}{ MTBM $(\min 0 r)$} & $\therefore 5258$ & $\therefore *+$ & 8113 & $\because .7413$ & -44756 & 5106 \\
\hline
\end{tabular}

italics - indicate "Inajor" lailures, requires engine warmup for repair

phin - indicate "Ininor" failures. engine does not require warmup for repair

MTBM- average "Mean Time Between Mantenance" in hours for the 24 enginas (see eqn 1)

*-Separate lifetime not applicable. Statistics included in 94-95 run value. 


\section{ANALYSIS OF FAILURE RATE ASSUMPTION}

As noted above in defining a MTBM, a constant failure rate is assumed. Quite often a more realistic situation is to have a somewhat high initial failure rate that decreases over time (reflecting start-up "infant mortality" failures), followed by some period of a constant failure rate (random failures), followed by a final period of increasing failure rate (wear-out failures). Often for individual components of a system, bearings for instance, wear-out failures will dominate. But for entire systems, such as an expansion engine, often a constant failure rate can be assumed over the majority of the operational life. This assumption can be checked by looking at a time-series chart in Figure 2. To make one clarification in this figure, recall that many of the warm end components during the 1994-95 run had not been rebuilt prior to this run. Since cold ends were indeed rebuilt, this run has different effective end-of-run times for the cold end and warm end components, as shown in Figure 2.

This data can be used to pertorm a "centroid test" to see if any trends are present. 6 If there are $n$ events, occurring at time $x_{i}$, for an observation period of $x_{0}$, then the test statistic for trend is:

$$
U=\frac{\sqrt{12 n}}{x_{0}}\left[\sum_{i=1}^{n} \frac{x_{i}}{n}-\frac{x_{01}}{2}\right]
$$

This compares the centroid of the observed arrival times with the mid-point of the observation period. If $U=0$, there is no trend, failure rate tends to be constant. If $U<0$, the trend is for a failure rate that decreases with time, that is the time between failures tends to become larger. If $U>0$, the trend is for a failure rate that increases with time. Further analysis can indicate whether or not a constant failure rate is a reasonable assumption for that period. The value of $\mathrm{U}$ can be used to test the null hypothesis that there is no trend in the ordered data by use of the standard cumulative normal distribution function. For example, at $U= \pm 1.65$, there is a $5 \%$ chance that such chronological ordering occurred with a constant failure rate; thus the null hypothesis can be rejected at the $5 \%$ statistical significance level. In engineering it is often typical to consider $5 \%$ or less statistical significance to be sufficient evidence upon which to reject a null hypothesis. But Table 4 shows that in many cases, one does not have this amount of confidence to reject the null hypothesis. Therefore, there is no highly statistically significant evidence to preclude the use of a constant failute rate assumption.

O major repairs $\Delta$ minor repairs $\quad$ end of run

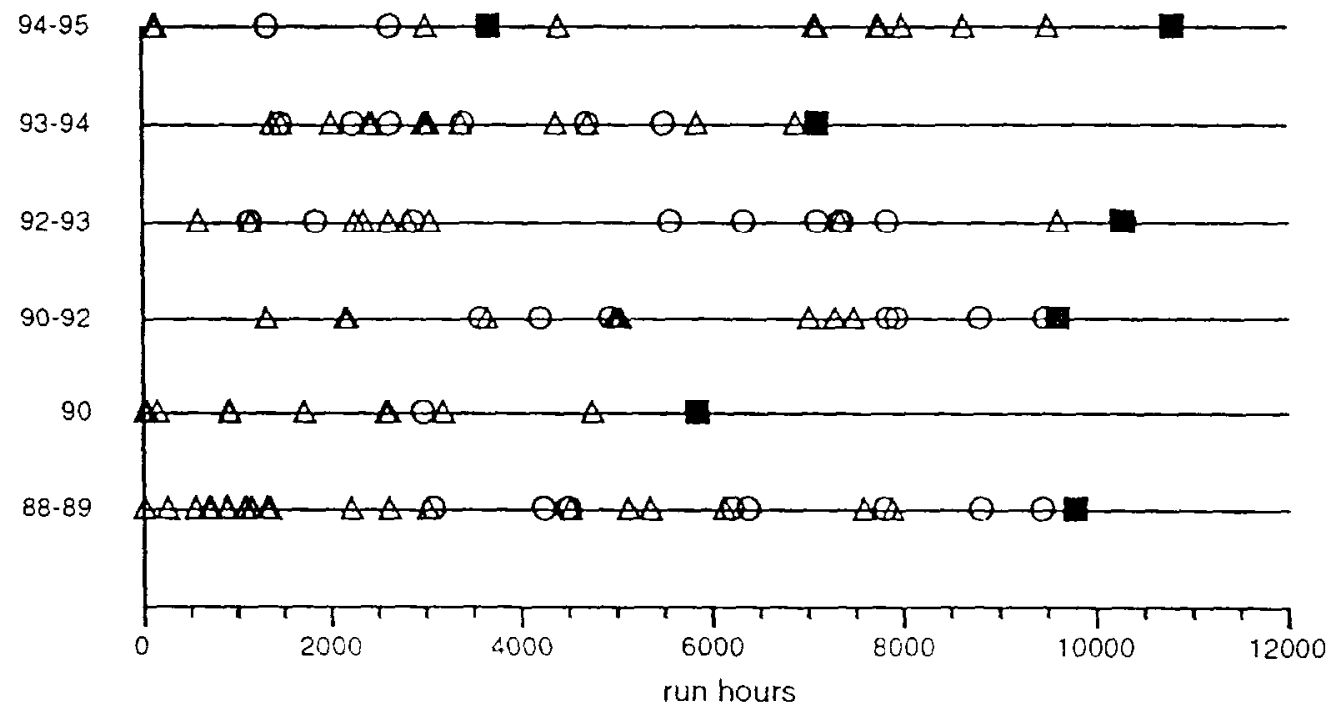

Figure 2. Time-series chat of failures for system of 24 wet expanders 
Table 4. Centroid U values and signilicance levels for trends

\begin{tabular}{|l|c|c|c|c|c|c|c|}
\cline { 2 - 7 } \multicolumn{1}{c|}{} & $94-95$ & $93-94$ & $92-93$ & $90-92$ & 90 & $88-89$ \\
\hline \hline U value & (major) & +0.19 & -0.03 & +0.69 & +1.80 & +0.05 & +1.55 \\
\hline significance for trend, \% & 42 & 49 & 24 & 3.6 & 48 & 6.1 \\
\hline U value & (minor) & -1.17 & -- & -1.96 & -0.49 & -0.95 & -3.90 \\
\hline significance for trend, \% & 12 & - & 2.5 & 31 & 17 & 0.005 \\
\hline
\end{tabular}

However in general, major failures can be seen to most probably have a failure rate that slightly increases over time due to wear-out. Minor failures most probably have a slightly decreasing failure rate trend, dominated by start-up troubles. Nevertheless, neither failure rate consistently shows an overwhelming trend. Overall, assuming a constant failure rate is adequate.

\section{FAILURE RATE ASSESSMENT}

For each run, an overall failure rate can be found by looking at the total number of failures divided by the total run hours. This is shown in Figure 3. This failure rate represents the average failure rate for one engine, based on a sample of 24 engines. One can use this to make judgments on the reliability of reciprocating cryogenic engines. It has an advantage over the MTBM values in that MTBM is influenced by when shutdown maintenance occurs. This figure offers a good comparison of maintenance trends over the last several years. Also, one can compare the reliability of the new larger piston wets to the original smaller piston wets.

In general the failure rate for minor maintenance items, those warm end parts that do not require engine warmup to repair, has increased during the last two runs. Recall, these are the runs using larger diameter pistons. Table 3 reveals that the last two runs have experienced increased failures of main bearings, connecting rod bearings, shafts, and frames in general. This was a consequence of the conversion to larger piston wet engines, which result in more force applied to the rotating shaft and bearings.

A specific illustration of this can be seen in Table 3 by noting the rash of crankshaft failures during 1993-94. The ultimate problem was latigue failure, accelerated by excessive fretting. The fretting corrosion mechanism will cause small pits and cracks at contacting surfaces, which serve as fatigue crack initiation sites. In response to this, the crankshaft now

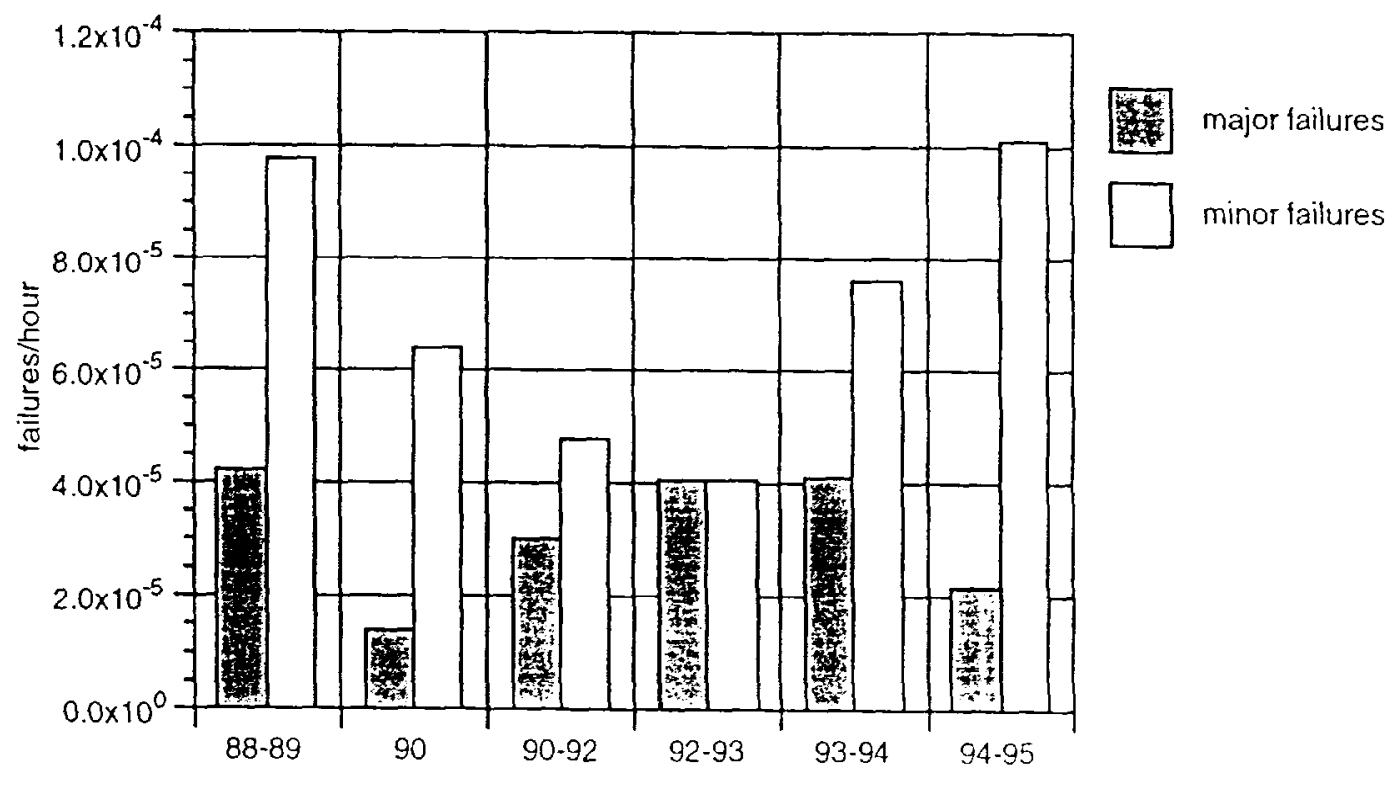

Figure 3. Wet engine favlure ralles 
is made of a higher strength steel and, most importantly, receives a surface treatment for hardening. The surface treatment induces residual compressive stresses at the surface,

inhibiting fatigue crack growth. There has not been a failure of a crankshaft with the superior varieties of surface treatments, ion-nitriding and a special chroming (a conventional chroming process could lead to hydrogen embrittlement and reduced fatigue strength). Crankshaft fretting certainly occurred in the original wet engines, but with the smaller forces there was more margin of safety.

Figure 3 shows that the failure rate for major repairs has remained about constant Recall, these failures mostly consist of piston O-ring failures. This failure rate in fact is a

function of run length. Notice that for the shorter runs in 1990 and 1994-95, failure rates are less. This indicates that wear-out failures dominate, as expected. There are virtually no changes in the major failure rate since the conversion to larger piston wets.

One line of Table 3 that bears explaining is the very high number of cold valve changes that took place during the 88-89 run. This was a consequence of a large number of contamination problems at the beginning of this run. This serves to elevate the minor failure rate for this run and also shift many of these failures to early in the run.

\section{CONCLUSIONS}

Through the years, reliable operation of Fermilab's reciprocating expansion engines has been demonstrated. To date about two million hours have been experienced at Fermilab. One now expects a mean time between major maintenance of about 7000 hours. This is an improvement on the mean times of 2000 to 3000 hours originally reported. ${ }^{7}$

In general, it is apparent that overall reliability with the $7.5 \mathrm{~cm}$ piston wets used since late 1993 is slightly less than that obtained with the $5 \mathrm{~cm}$ piston wets. This is attributable to an increase in minor maintenance, repairs that do not require engine warmup. Major failure rates are virtually unchanged. Since there has been a slight increase in minor failure rate, some improvements could be made in strengthening the frame components that now experience larger stress. Another alternative would be to perform warm component overhauls more frequently.

\section{ACKNOWLEDGMENTS}

The author wishes to thank the current staff of the Accelerator Cryogenics Engine Group: Ronald Norton, Michael Barbor, Daniel Freeman, Barry Skinner, and Derrick West. It is their skill and dedication, as well as the contributions made by earlier engineers and technicians in this group, that keep our expansions engines working so reliably.

\section{REFERENCES}

1. T. J. Peterson, Fermilab's satellite refrigerator expansion engines, "Advances in Cryogenic Engineering," Vol. 29, Plenum Press, New York (1984), p. 443-451.

2. J. C. Theilacker, Current operating experience and upgrade plans of the Tevatron cryogenic system, "Advances in Cryogenic Engineering," Vol. 35B, Plenum Press, New York (1990), p. 917-23.

3. B. L. Norris and J. C. Theilacker, Tevatron operational experiences, "Supercollider," Vol.1, Plenum Press, New York (1989), p. 321-28.

4. B. L. Norris, Status report on the Tevatron lower temperature upgrade, "Cryogenics," Vol. 34 ICEC supplement, Butterworth-Heinemann, London (1994), p. 73-76

5. P. D. T. O'Conner. "Practical Reliability Engineering," 3rd ed., John Wiley and Sons, Chichester England (1991), p. 4, 7, 38 .

6. Ibid., p. 60-61.

7. Peterson, expansion engines, p. 449. 